\title{
Evaluation of Economic Efficiency of Territory Development
}

\author{
Jana Korytárová ${ }^{1}$, Vít Hromádka ${ }^{2}, M^{\prime}$ artin Marek $^{3}$, Svatopluk Pelčák $^{4}$ and Jiří Rouzek \\ ${ }^{1}$ Brno University of Technology, Faculty of Civil Engineering, Veveř́ 331/95, 60200 Brno, Czech \\ Republic, korytarova.j@fce.vutbr.cz \\ ${ }^{2}$ Brno University of Technology, Faculty of Civil Engineering, Veveř́ 331/95, 60200 Brno, Czech \\ Republic, hromadka.v@fce.vutbr.cz \\ ${ }^{3}$ Brno University of Technology, Faculty of Civil Engineering, Veveří 331/95, 60200 Brno, Czech \\ Republic, Martin.Marek3@vutbr.cz \\ ${ }^{4}$ Brno University of Technology, Faculty of Civil Engineering, Veveři 331/95, 60200 Brno, Czech \\ Republic, 167293@vutbr.cz \\ ${ }^{5}$ Brno University of Technology, Faculty of Civil Engineering, Veveř́ 331/95, 60200 Brno, Czech \\ Republic,156940@vutbr.cz
}

\begin{abstract}
The article deals with the analysis of background resources for the evaluation of socioeconomic impact methodology elaboration of the territory development in the field of commercial, service and residential properties, mixed constructions and multifunctional buildings in the first phase of their life cycle. The research team investigated the possibilities of using the information and procedures for the evaluation of socio-economic impacts of the territory development. Relevant data for the evaluation was identified and analysed on the research sample of 12 major urban districts of the city of Brno. Technical and social parameters that appeared relevant for the economic evaluation of the surveyed location development were identified based on the available data on individual territories. The first identification step was their description. Subsequently, suitable metrics for their evaluation were examined. Findings about what socio-economic impacts these locations create in the field of interest and whether these impacts are efficient in terms of their functioning represent the output of the paper. This includes determining the overall economic efficiency of the implementation phase of their life cycle. This output then forms base for the future research focusing on the possibility of including other variables that shall focus on the operational phase of the life cycle and extend the assessment to a wider timeframe.
\end{abstract}

Keywords: Territory Development, Socio-Economic Evaluation, Multicriteria Analysis.

\section{Introduction}

The method of assessing the economic efficiency of the territory development depends on the extent and specifications of the technical determination of the change in the current situation. From the development point of view, it can be a specific large-scale development project, for which the basic project documentation has already been elaborated at the architectural study level; furthermore, one of the stages of the project documentation can be processed for a particular sub-project. At the level of information provided by the specific technical documentation, it is possible to evaluate their economic efficiency with a certain amount of experience and knowledge, e.g. using the CBA method (projects of road and highway sections, railway corridors, waterways, specific buildings for civil or commercial purposes (Guide, 2014)). The authors of this article focus on a more general view of the territory development and its future potential use, already at the land use plan level. At this level, no specific 
development projects are defined, however the territory is being prepared for a specific use or combination of uses. The land use plan sets out the urban concept, the concept of landscape arrangement and the concept of public infrastructure, it defines the built-up area, areas and corridors and sets the conditions for the use of these areas.

The research is aimed at finding suitable criteria that can be used to assess the socioeconomic efficiency of the territories that are defined as areas or sets of areas, or parts of areas, defined on the basis of the prevailing character. The individual areas constituting the territory may be areas for housing, recreation, civic amenities, mixed residential, transport infrastructure, technical infrastructure, production and storage, mixed production, public areas, green areas, water and water management, agricultural, forest, natural, mixed undeveloped areas, mineral extraction and specific. The research question is whether the territories formed by the combination of the above-mentioned areas can be expressed by economic quantity that would prove their efficiency level. The municipality, in which cadastral the territory is located has to incur certain expenditures on preparation for its intended use. The question is whether there may be any revenues and/or socio-economic benefits that the new territory can bring to the municipality/society.

\section{Analysis of the Current Situation}

Urban sustainability is a multi-dimensional concept that includes environmental, economic, social and political dimensions (Huang et al., 2009; Olewiler, 2006). The strategic plan towards sustainable developne opportunities, the loca (Scipioni et al., 2009 Moussiopoulos (2010) namely: (I) Econony

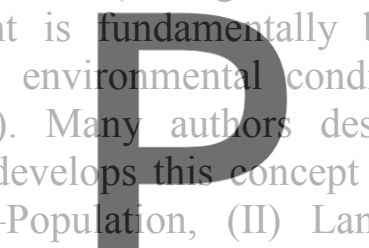

Transportation, (V) Agriculture-Livestock-Fishery, Pollution-Climate Change, (IX) Water Resources and Sea Environment, (X) Solid Waste, (XI)

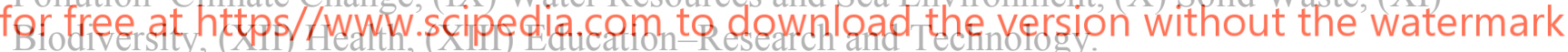

(Nijkamp, 1995) sets main criteria and sub-criteria following A. Functional restructuring of the area (residential, tertiary and cuitural function), B. Economic valorisation of the area (property value of real estate, commercial value, socio-economic value), C. Common utility (public recreational and supporting services) and D. Historic - environmental value (conservation and restoration value, aesthetic aspect of urban assets, integration with the historical city center).

For deciding on effective activities in the area it is sometimes necessary to quantify these variables. Research of the authors in the first phase focused only on a part of economic and socio-economic aspects, where it was able to define technical and socio-economic input variables, create their aggregation and produce relevant outputs.

\section{Methodology}

Changing the location purpose from the current prevailing use to another entails certain costs that the municipality has to incur in order to implement the new use of the location. These are mainly requirements for the construction of roads and backbone networks. At the same time, changes in the use of locations, depending on their character of the usable areas, can bring a 
certain capacity of new residents and new jobs.

In order to work effectively with the technical-economic data, the characteristics of the locations were primarily defined. The basic attribute for their determination was the structure of the layout of the individual areas of the location, which may be residential (r), compact (c), empty (e), construction limited (1) or zoned (z). Average lengths of roads and backbone networks in $\mathrm{m} / \mathrm{ha}$ were determined for each structure. Furthermore, possible incremental capacities of permanent residents and incremental capacities of new jobs were determined for each location. These data, which create important inputs into analysis presented in this paper, were taken from the results of the relevant scientific research oriented on evaluation of development opportunities prepared and proposed for the land use plan.

Based on the average length of roads and backbone networks in $\mathrm{m} / \mathrm{ha}$ (water, sewerage, gas, electricity, central heating), including their average technical parameters together and their average unit prices according to national price databases, the cost in $€ /$ ha was determined for each location and the cost in $€ / \mathrm{m} 2$ was derived from them. The total cost of the change in the use of the location (Criterion K1) is the sum of the costs of the areas that the location contains.

$$
K 1=\sum_{i=1}^{n} C A_{i}
$$

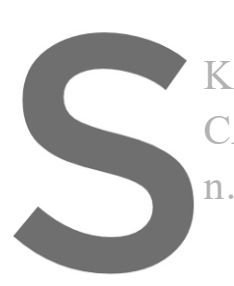

\section{Where}
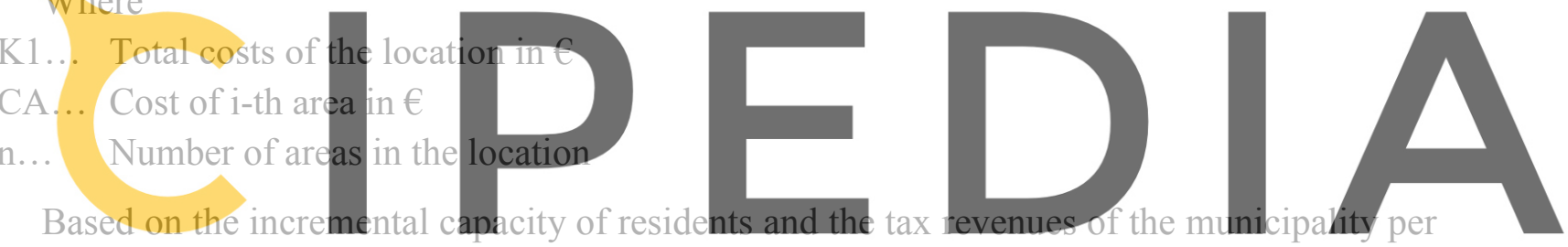

capita, the potential revenue of the municipality (Criterion K2) can be determined according to

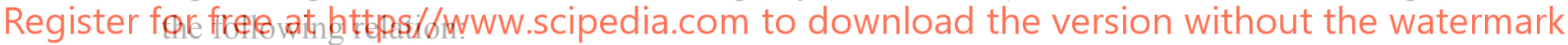

$$
K 2=I \times R_{T}
$$

Where

$\mathrm{K} 2 \ldots$ Total revenue of the location in $€$

I... Incremental capacity of residents

$\mathrm{R}_{\mathrm{T}} \ldots$ Tax revenue of the municipality per capita in $€ /$ cap.

The potential social benefit (Criterion K3) was determined on the basis of the incremental capacity of the new jobs in the location, where the unit of benefit is the socio-economic benefit arising for the company in creating one new job.

$$
K 3=L \times B_{J}
$$

Where 
K3 ... Total socio-economic benefits of the site in $€$

L... Incremental capacity of jobs

$\mathrm{B}_{\mathrm{J}} \ldots$ Benefit of the society from one created job in $€ /$ job

The output of the economic model is the determination of the overall location efficiency $(\mathrm{E})$, which is defined as the sum of the product of the location classification values in a given criterion $(\mathrm{K})$ and its weight $(\mathrm{w})$.

$$
E=\sum_{i=1}^{n} K_{i} \times w_{i}
$$

The rating scale for each criterion values are listed below. The criteria weights were expertly chosen as follows:
Criterion K1 weight $w_{1}=0.60$,
Criterion $\mathrm{K} 2$ weight $w_{2}=0.20$,
Criterion K3 weight $w_{3}=0.20$.

According to the fact that this is a "yield" criterion, higher value of overall efficiency E represents higher efficiency of the territory.

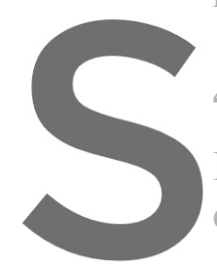

4 Results

Interim research results

of 12 locations boroughs
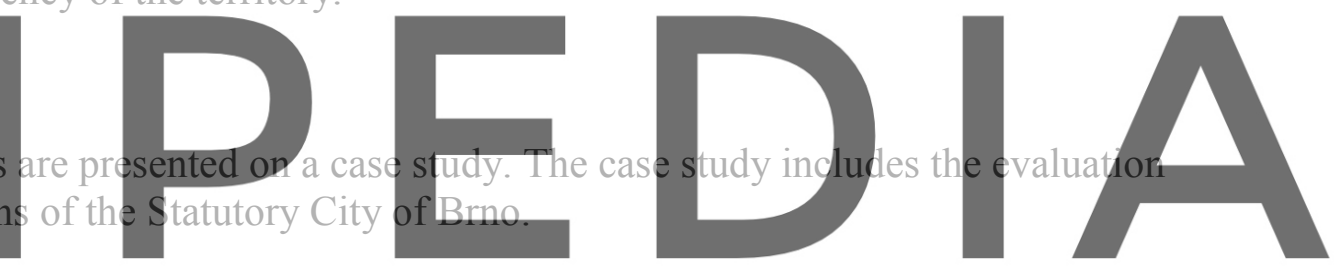

4.1 Vallues of Input Variables

Register for free at https//www scipedia, com to downdoad the version without the watermark for individual representatives of the location structures. The values are given in Table 1.

Table 1. Model costs of the backbone network in $€ /$ ha.

\begin{tabular}{ccrrrr}
\hline $\begin{array}{c}\text { Type of } \\
\text { structure }\end{array}$ & $\begin{array}{l}\text { Cost of } \\
\text { Water }\end{array}$ & $\begin{array}{c}\text { Cost of- } \\
\text { Sewerage } \\
{[€ / \mathrm{ha}]}\end{array}$ & $\begin{array}{c}\text { Cost of } \\
\text { Gas } \\
{[€ / \mathrm{ha}]}\end{array}$ & $\begin{array}{c}\text { Cost of } \\
\text { Electricity } \\
{[€ / \mathrm{ha}]}\end{array}$ & $\begin{array}{c}\text { Cost of } \\
\text { Central } \\
\text { Heating } \\
{[€ / \mathrm{ha}]}\end{array}$ \\
\hline $\mathbf{r}$ & 141,438 & 100,836 & 67,140 & 36,633 & 391,744 \\
\hline $\mathbf{c}$ & 118,206 & 84,273 & 56,112 & 30,616 & 327,397 \\
\hline $\mathbf{e}$ & 157,267 & 112,120 & 74,653 & 40,733 & 435,583 \\
\hline $\mathbf{I}$ & 61,882 & 44,118 & 29,375 & 16,028 & 171,396 \\
\hline $\mathbf{z}$ & 120,436 & 85,863 & 57,170 & 31,194 & 333,575 \\
\hline
\end{tabular}

The costs of roads by length per hectare were further divided into groups according to the 
assumed width of the road, considering the widths of 8,12 and $24 \mathrm{~m}$. The values obtained are shown in Table 2.

Table 2. Model costs of roads in the territory according to their widths in $€ /$ ha.

\begin{tabular}{crrr}
\hline $\begin{array}{c}\text { Type of } \\
\text { structure }\end{array}$ & $\begin{array}{c}\text { Width 8 } \mathbf{~ m} \\
{[€ / \mathrm{ha}]}\end{array}$ & $\begin{array}{c}\text { Width 12 m } \\
{[€ / \mathrm{ha}]}\end{array}$ & $\begin{array}{c}\text { Width 24 m } \\
{[€ / \mathrm{ha}]}\end{array}$ \\
\hline $\mathbf{r}$ & 228,275 & 342,413 & 684,826 \\
\hline $\mathbf{c}$ & 190,779 & 286,169 & 572,338 \\
\hline $\mathbf{e}$ & 253,821 & 380,732 & 761,464 \\
\hline $\mathbf{I}$ & 99,875 & 149,813 & 299,625 \\
\hline $\mathbf{z}$ & 194,379 & 291,569 & 583,137 \\
\hline
\end{tabular}

The value of revenue per capita used is based on the statistical data of the set municipality, in the case of the mentioned case study - the final account of the Statutory City of Brno (SCB, 2018) in the current value of $€ 1,020$ /resident.

The average value of a socio-economic benefit arising for a society in creating one job without considering specific job positions is assumed for the Czech Republic at the current value of $€ 12,401 /$ job (SEI, 2019).
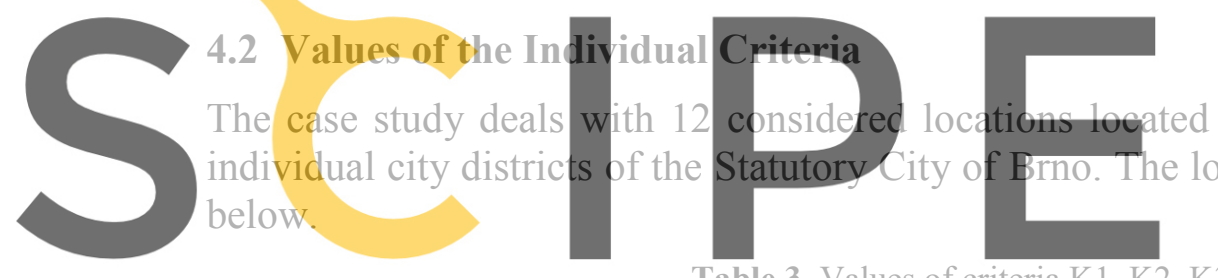

Table 3. Values of criteria K1, K2, K3 v $1 / \mathrm{m} 2$
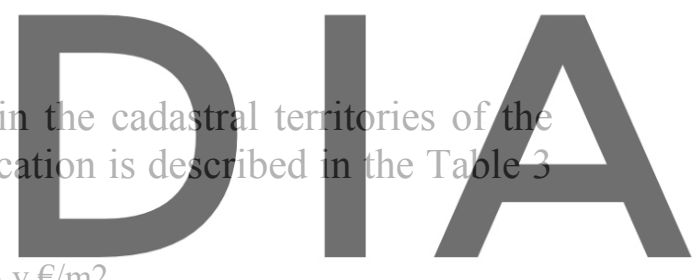

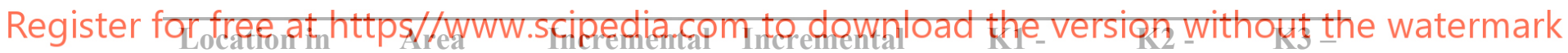

\begin{tabular}{ccrrrrr}
$\begin{array}{l}\text { the cadlastrall } \\
\text { area }\end{array}$ & ha & $\begin{array}{r}\text { capacity of } \\
\text { residents }\end{array}$ & $\begin{array}{r}\text { capacity of } \\
\text { jows }\end{array}$ & $\begin{array}{r}\text { costs } \\
\mathbf{\epsilon} / \mathbf{m}^{2}\end{array}$ & $\begin{array}{r}\text { revenues } \\
\mathbf{C} / \mathbf{m}^{2}\end{array}$ & $\begin{array}{r}\text { benefits } \\
\mathbf{\epsilon} / \mathbf{m}^{2}\end{array}$ \\
\hline Prizrenice 1 & 62.52207 & 2,736 & 3,871 & 55.47 & 106.88 & 76.80 \\
\hline Prizrenice 2 & 58.32664 & 3,215 & 4,272 & 57.70 & 125.59 & 90.82 \\
\hline Cernovice 1 & 39.97897 & 458 & 4,668 & 65.20 & 1.17 & 144.80 \\
\hline Bosonohy 1 & 39.72692 & 1,407 & 874 & 45.00 & 3.63 & 27.27 \\
\hline Reckovice & 38.96985 & 4,033 & 1,959 & 55.63 & 10.55 & 62.34 \\
\hline Styrice & 38.76289 & 883 & 674 & 87.77 & 10.86 & 261.56 \\
\hline Bosonohy 2 & 34.87699 & 28 & 2,030 & 53.32 & 5.43 & 187.89 \\
\hline Komin & 32.67942 & 982 & 573 & 47.34 & 3.09 & 21.76 \\
\hline Bohunice & 31.46935 & 3,031 & 1,966 & 59.61 & 9.84 & 77.46 \\
\hline Dolni Herspice & 30.93395 & 90 & 1,807 & 55.31 & 0.31 & 72.46 \\
\hline Prizrenice 3 & 30.68411 & 3,612 & 944 & 61.33 & 12.03 & 38.16 \\
\hline Cernovice 2 & 28.72383 & 380 & 3,191 & 62.42 & 1.37 & 137.77 \\
\hline
\end{tabular}




\subsection{Description of Classification Grades to Calculate the Overall Location Efficiency}

For all the above-mentioned evaluation criteria, the following tables show the methods of their evaluation based on the classification according to the selected categorisation.

\section{Criterion $\mathrm{K} 1$ - classification scale for cost value intervals per $\mathbf{m}^{2}$}

In terms of their cost per $\mathrm{m}^{2}$, the assessed locations were divided into 5 classification grades ( 1 - least expensive, 5 - most expensive) according to the cost intervals given in the following Table 4.

Table 4. Classification grades for the cost interval per $\mathrm{m} 2$ of the designed location area.

\begin{tabular}{ccc}
\hline Cost interval per $\mathbf{~ m}^{\mathbf{2}}\left[\boldsymbol{E} / \mathbf{m}^{\mathbf{2}}\right]$ & Descriptor & Classification grade \\
\hline$<39.06$ & Low cost & 1 \\
\hline $39.06-58.58$ & Lower cost & 2 \\
$58.59-78.13$ & Average cost & 3 \\
$78.14-97.66$ & Highest cost & 4 \\
\hline$>97.66$ & High cost & 5 \\
\hline
\end{tabular}

Criterion $\mathbf{K} 2$ - classification scalle for revenue value intervals per $\mathrm{m}^{2}$

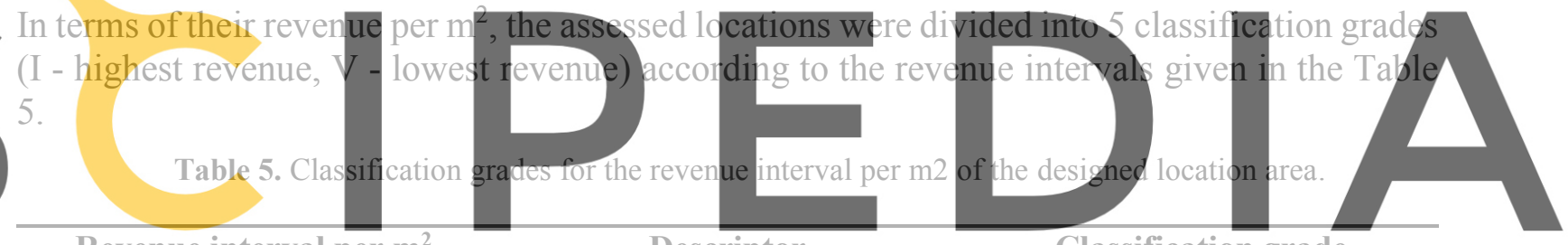

Revenue interval per $\mathrm{m}^{2}$

Descriptor

Classification grade

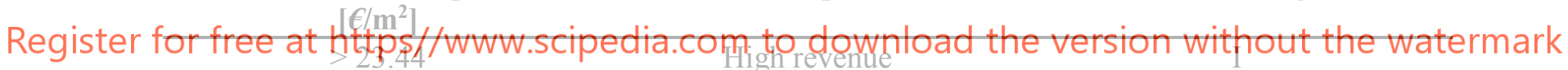

\begin{tabular}{ccc}
\hline $20.35-23.44$ & Higher revenue & II \\
\hline $9.78-20.34$ & Average revenue & III \\
\hline $3.91-9.77$ & Lower revenue & IV \\
\hline$<3.91$ & Low revenue & V \\
\hline
\end{tabular}

Note: For the calculation of the overall efficiency for this yield criterion, the classification grade "I" $=5$ points, the classification grade " $V$ " 1 point (higher revenue is preferred).

\section{Classification scale for the social benefits value interval}

The assessed locations were divided into 5 classification grades (A to E, A - highest social benefit, $\mathrm{E}$ - lowest social benefit) according to their societal benefit intervals given in Table 6 . 
Table 6. Classification scale for social benefits interval per $\mathrm{m} 2$ of the designed location area.

\begin{tabular}{ccc}
\hline $\begin{array}{c}\text { Social benefit interval per } \\
\mathbf{m}^{\mathbf{}} \boldsymbol{\epsilon} / \mathbf{m}^{\mathbf{2}}\end{array}$ & Descriptor & Classification grade \\
\hline$>97.66$ & High benefit & $\mathrm{A}$ \\
\hline $58.65-97.66$ & Higher benefit & $\mathrm{B}$ \\
\hline $19.54-58.64$ & Average benefit & $\mathrm{C}$ \\
\hline $3.90-19.53$ & Lower benefit & $\mathrm{D}$ \\
\hline$<3.90$ & Low benefit & $\mathrm{E}$ \\
\hline
\end{tabular}

Note: For the calculation of the overall efficiency for this yield criterion, the classification grade " $A$ " $=5$ points, the classification grade " $E$ " $=1$ point (higher benefit is preferred).

\subsection{Resulting Ranking of the Locations According to Overall Efficiency}

Table 7 shows the evaluation of locations according to individual classification grades and the overall efficiency of the location E according to the above-listed relation is determined as the sum of the products of the classification grade values in the relevant criterion and its weight.

Table 7. Overall efficiency of the locations, sorted by the value of the overall efficiency E descending.

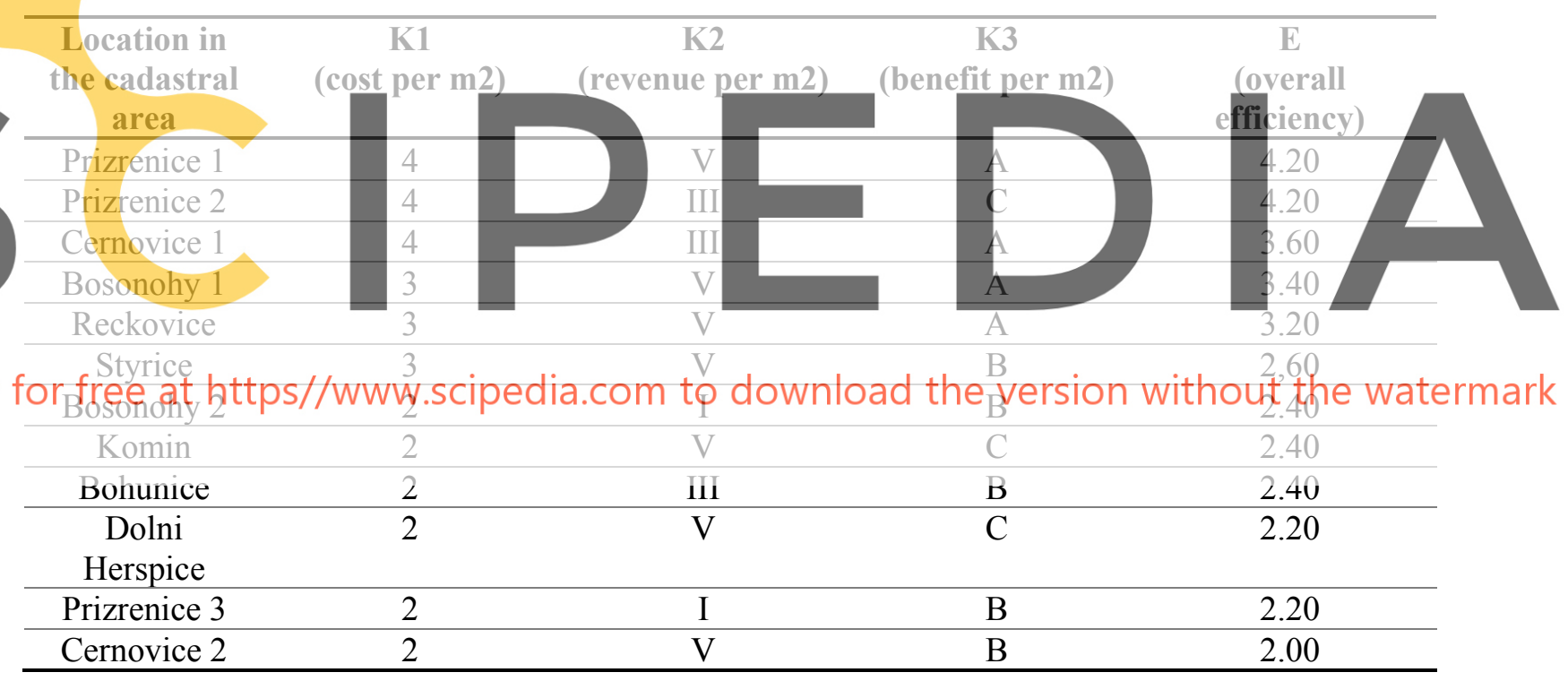

Locations are sorted according to values of efficiency, according to the values of individual criteria is also clear how the individual criteria for overall efficiency involved. The overall efficiency ranges from 2 to 4.2 points of the 5-point scale.

\section{Conclusion}

The article deals with determination of the procedure for the evaluation of the economic efficiency of designed locations. The economic evaluation is made to compare the extent of economic intensity, potential revenue and socio-economic benefit of individual development 
locations among themselves and to determine the possible succession for their implementation - a change in their use. For this reason, an economic model of costs, revenues and benefits related to the transformation of the current location into its proposed use was developed. The economic model is designed for the basic economic awareness of the costs, revenues and benefits of the areas under consideration at the level of detailed technical data that are part of the land use plan. For this reason, it works with the average values of the territory representatives. Value analysis procedures were chosen for comparison of designed locations. Future research will focus on another part of the life cycle of the municipal property thus created, namely the cost of repairing and maintaining in the operational phase, where it will be necessary, among others, to examine its average lifetime.

\section{Acknowledgements}

This paper has been worked out under the project of the specific research at Brno University of Technology no. FAST-S-20-6383 Selected Economic and Managerial Aspects in Construction Engineering

\section{ORCIID}

Jana Korytárová: http://orcid.org/0000-0002-0046-0141

Vít Hromádka: http://orcid.org/0000-0002-9590-9828

\section{References}

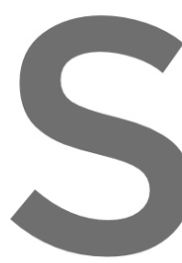

Huang, S. L., Yen, C. T., Budd, W development in Taiwan based on

Olewiler, N. (2006) Environmental 23(3), 184-195.

Scipioni, A., Mazzi, A., Masen, M. a
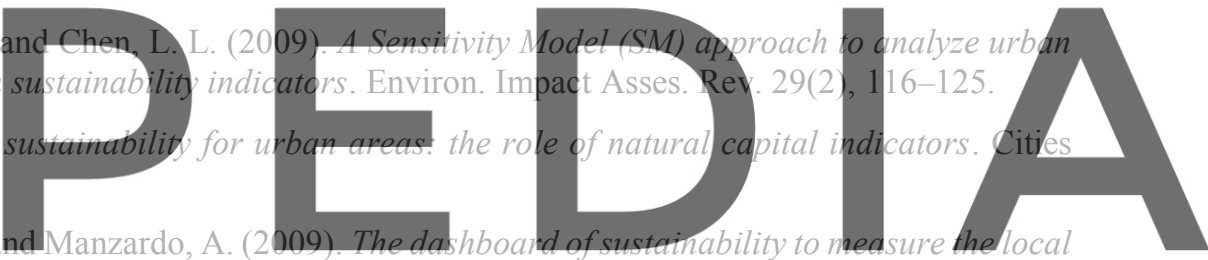
urban sustainable development: the case study of Padua Municipality. Ecol. Indic. 9(2), 364-380.

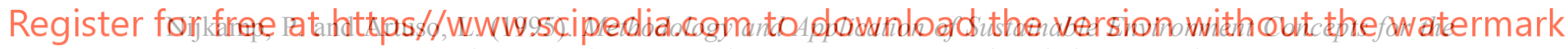
Built Environment, Cerie Research Memoranda, 1995-48, VRIJE Universiteit, Amsterdam.

Moussiopoulosa, N., Achillasa, Ch., Vlachokostasa, Ch., Spyridia D. and Nikolaoub, K. (2010). Environmental, social and economic information management for the evaluation of sustainability in urban areas: A system of indicators for Thessaloniki, Greece, Cities, Volume 27, Issue 5, October 2010, Pages 377-384. https://doi.org/10.1016/j.cities.2010.06.001

Statutory City of Brno (SCB, 2018). The final account of the Statutory City of Brno, Brno City Hall, Budget and Finance Department.

Database of socio - economic impacts of OPEI (SEI, 2019). Available from https://www.agenturaapi.org/cs/metodika/ekonomicke-hodnoceni/

Guide to Cost-Benefit Analysis of Investment Projects (Guide, 2014). Economic Appraisal Tool for Cohesion Policy 2014-2020, European Commission, Directorate-General for Regional and Urban Policy. 